\title{
A Review of Trimen's False Tiger Moth, Agoma trimenii (Lepi- doptera: Agaristidae): Seasonal Biology, Potential Monitoring and Control Techniques
}

\author{
C.A. Morris ${ }^{1}$, S.A. Johnson ${ }^{1, *}$, J.Y. De Waal ${ }^{2}$, A.P. Malan ${ }^{1}$ \\ (1) Department of Conservation Ecology, Stellenbosch University, Private Bag X1, Matieland (Stellenbosch), South Africa \\ (2) Corteva Agriscience ${ }^{\mathrm{TM}}$, South Africa
}

Submitted for publication: February 2020

Accepted for publication: May 2020

Key words: Agoma trimenii, grapevine, monitoring, Trimen's false tiger moth

\begin{abstract}
Trimen's false tiger moth, Agoma trimenii (Lepidoptera: Agaristidae), has recently been found to occur in vineyards in the Northern Cape and Limpopo (Groblersdal area) provinces of South Africa. As little is known about the biology and behaviour of the moth, no official monitoring methods or economic thresholds relating to it exist. Consequently, management and registered control options still require development. The first aim of the current review was to gather and critically discuss all the available information on A. trimenii in the context of the information gained from field observations conducted in the Northern Cape during the 2016/2017 and 2017/2018 seasons. The paper also includes reporting on field observations made with regard to various aspects of the seasonal life cycle and ecology of $A$. trimenii, with a view to investigate, in future research, the potential biological control options available. Potential monitoring strategies of $A$. trimenii in the field were investigated. Various life stages of $A$. trimenii were identified, peak flight times were established, overlapping generations were determined, and the behavioural traits of all life stages were documented. Ultraviolet blue light traps proved to be the most promising potential monitoring strategy, with the prospect for an $A$. trimenii pheromone lure holding potential as an alternative monitoring strategy in the future. In summarising all current information on $A$. trimenii, recommendations for growers to monitor and control $A$. trimenii are presented towards the development of an integrated pest management system for the moth.
\end{abstract}

\section{INTRODUCTION}

South Africa is a major contributor to the worldwide export of table grapes, having produced an estimate of 59.4 million cartons during the 2018/2019 season (SATI, 2019). Table grapes are prone to outbreaks of various pest arthropods, and damage may occur directly to the fruit or indirectly by weakening the plant. Both types of damage negatively affect grapevine production.

Agoma trimenii (Felder) (Lepidoptera: Agaristidae), Trimen's false tiger moth, was first described in 1874 in subtropical Africa (De Prins \& De Prins, 2012) and has recently been found to occur in parts of South Africa, following reports of moth presence in vineyards in the summer rainfall areas (Pretorius et al., 2012). Members of the Agaristidae exhibit great diversity in other parts of the world, where they are also known to occur on vines. The painted vine moth, Agarista agricola (Donovan) (Beutenmüller), and the grapevine moth, Phalaenoides glycinae (Lewin), are both common insects that occur on vines in Australia (Australian Museum, 2010).
Knowledge relating to the biology and life cycle of A. trimenii is limited, and consequently there is a need for a monitoring system for this pest. Improved knowledge of $A$. trimenii would assist in decision-making on and the application of control options towards developing and implementing an integrated pest management (IPM) strategy for the pest. The aim of the current review and preliminary research study was to gather and critically discuss all the available information on $A$. trimenii, in the context of new information gained from field observations conducted in the Northern Cape province, South Africa, during the 2016/2017 and 2017/2018 seasons (Morris, 2018). To improve our understanding of the seasonal cycle, biology and behaviour of $A$. trimenii, field observations included visual scouting, recording behaviour and damage, morphological observations of the different life stages, and small-scale testing of trapping techniques. The paper reports on the first of such observations done on A. trimenii in South Africa.

*Corresponding author: E-mail address: sjohnson@sun.ac.za

Acknowledgements: The authors would like to thank the South African Table Grape Industry (SATI) and the National Research Foundation (NRF-THRIP. TP2011060100026), for funding of the project 


\section{GEOGRAPHICAL RANGE}

Both the introduction of $A$. trimenii to South African vineyards and its origin are uncertain, as no previous record of the presence of this moth species on any crop exists prior to 2012 (Pretorius et al., 2012). In South Africa, A. trimenii is present in the Northern Cape and Limpopo provinces. Beyond the South African borders, A. trimenii is known to occur in the Democratic Republic of the Congo, Ethiopia, Gambia, Kenya, Malawi, Mozambique, Niger, Nigeria, Senegal, Sierra Leone, Somalia, Sudan, Togo, Uganda, Zambia and Zimbabwe (De Prins \& De Prins, 2012; Pretorius et al., 2012). Reports limit the presence of $A$. trimenii to the African continent.

\section{HOST RANGE}

The feeding of the larvae of $A$. trimenii is described as being host-specific (Picker et al., 2002). Known host plants are wild grapes (Vitaceae) belonging to the Cissus and Rhoicissus genera (Pretorius et al., 2012). Reports of damage to the leaves of Cyphostemma cirrhosum (Thunb.) (Vitaceae) have also been recorded (De Prins \& De Prins, 2012). Within the Limpopo and Northern Cape, damage to the leaves of table grapes, wine grapes and raisin grapes has been reported (Pretorius et al., 2012).

\section{LIFE AND SEASONAL CYCLE}

Pretorius et al. (2012) reported that, in the Northern Cape province, moths are visible in vineyards between October and March, predominantly during the harvesting of wine grapes during January. Field observations conducted during the growing season and harvest time of the table grapes (from October 2017 to May 2018 - week 41 to week 19), comprising a 33-week period, indicate that $A$. trimenii can have four overlapping generations during that time. This was determined by visual scouting and recording the presence/ absence of adult moths, larvae on the vines and pupae in the soil in demarcated sites on two table grape farms in the Northern Cape every day over the 33-week period (Fig. 1): site 1 with table grape variety Thompson Seedless (THS); and site 2 with table grape variety Sugraone (SSD). The demarcated areas on both of the farms were not treated with pesticides or fungicides for the duration of the observational study. Within each month during the 33-week period, counts of adult moths and larvae were carried out for a seven- to 10day period according to the system developed and described by De Villiers and Pringle (2008) (Figs 2 and 3).

Peak flight times were recorded in mid-October and mid-December, as well as at the beginning of February, and finally towards the end of March (Fig. 1). Female moths deposit their eggs singly on the surface of grape leafs, from which the eggs begin to hatch after approximately three days (Pretorius et al., 2012). Visual scouting indicated that the single eggs are laid on the adaxial surface of the leaves in the top parts of the canopy of the vines. The length of time for larval development (from hatching to pupation) ranged from five to six weeks, according to the time interval between the first presence of the larvae after first moth flight to pupation before the next moth flight (Fig. 1). The first instar larvae disperse and feed on vegetative tissue, particularly on new shoots and leaves. The larvae continue to feed, and undergo numerous moults (exact number not yet determined), until they reach their final instar stage. Final instar larvae drop from the plant, via a silken thread, and burrow into the soil to a maximum depth of $4 \mathrm{~cm}$ in the soil mounds surrounding the vine. They remain in a soft-bodied prepupal state until they develop into fully formed, hardened pupae. Burrow holes (diameter of $\pm 2 \mathrm{~cm}$ ) are visible in the soil. The pupae were found in the soil around the vines within a radial range of 15 to $70 \mathrm{~cm}$. Most were located closer to the middle of the vineyard block than to the perimeter. During the season, pupal development in the soil took \pm three weeks before the adult moths emerged. The last generation enters diapause and overwinters as pupae in the soil, only to emerge as adult moths when temperatures become favourable again and new vegetative tissue grows on the vines.

\section{MORPHOLOGY}

As described by Pretorius et al. (2012), adults of $A$. trimenii are of medium size, with a wingspan of approximately $54 \mathrm{~mm}$. A black-grey border outlines the black forewings,

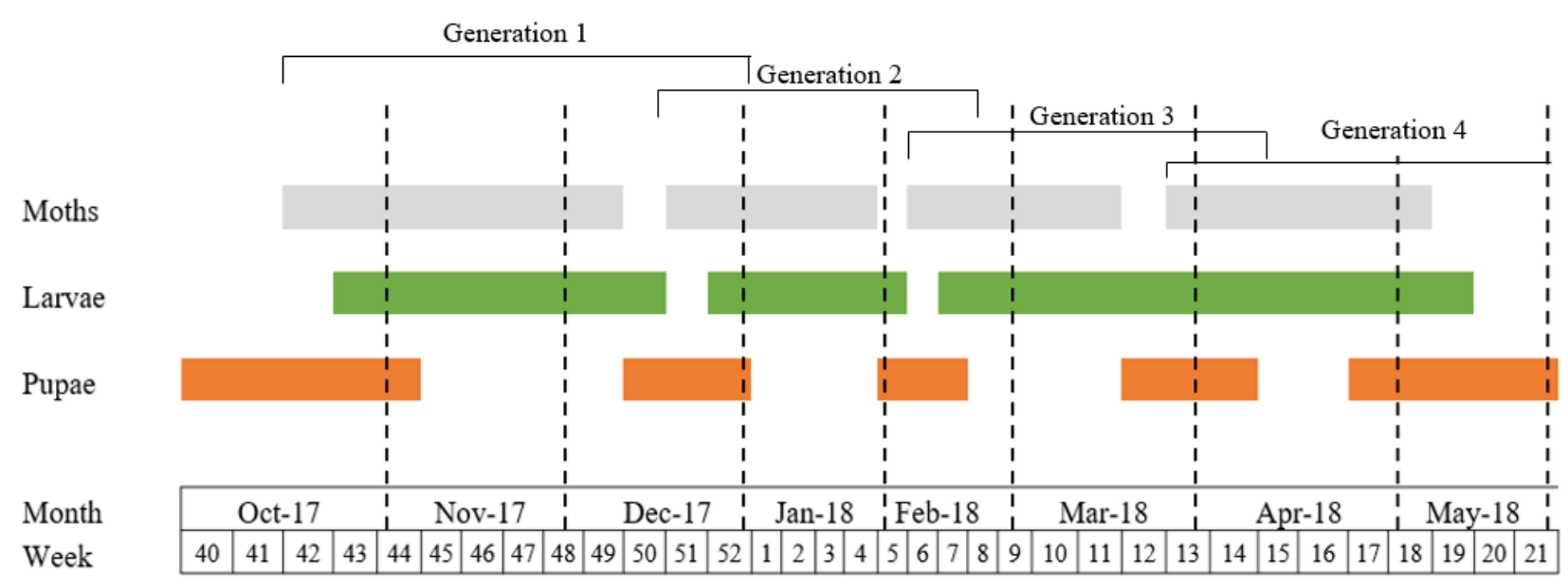

FIGURE 1

Presence of different life stages of Agoma trimenii from October 2017 to May 2018. Horizontal bars represent the presence of moths (grey), larvae (green) and pupae (orange) 


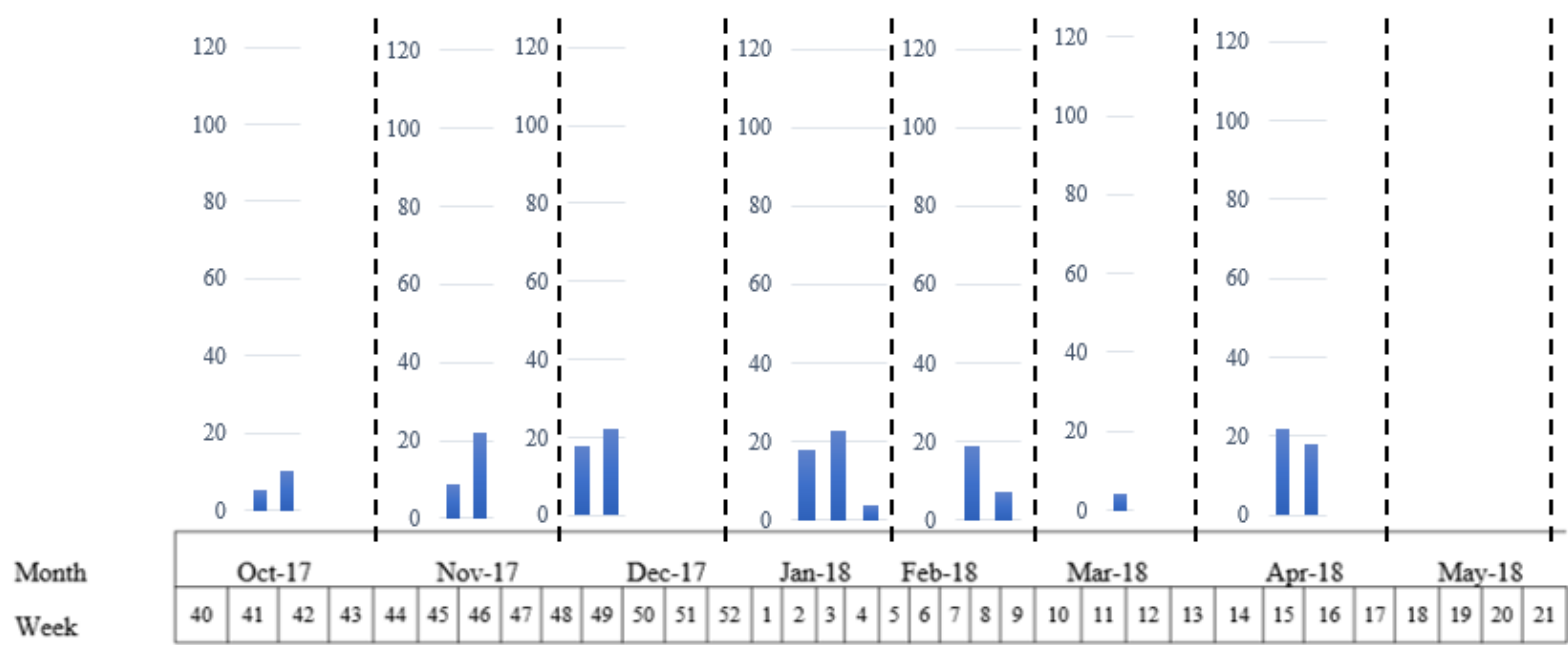

\section{FIGURE 2}

Agoma trimenii adult moth counts during monitoring period October 2017 to May 2018. Vertical bars represent moth counts over the seven- to 10-day periods per month

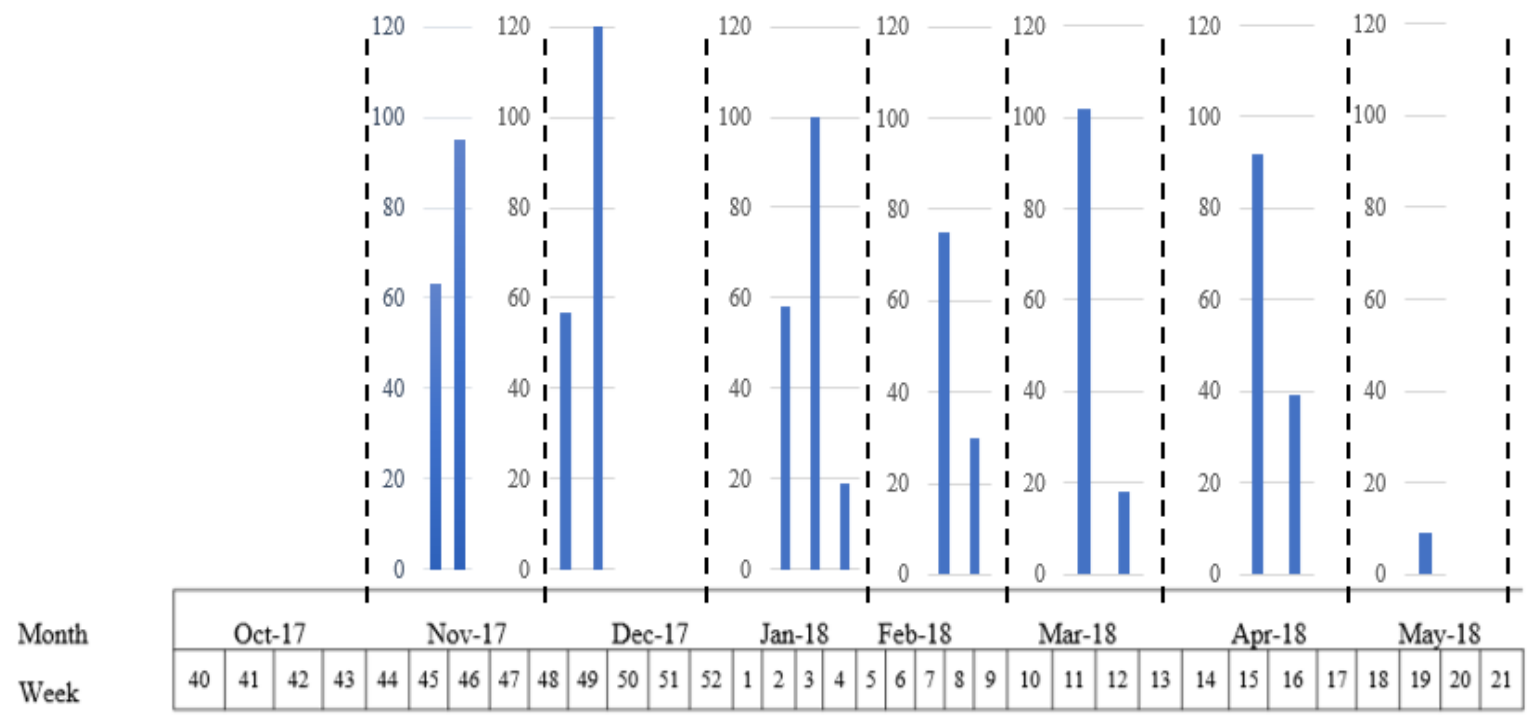

FIGURE 3

Agoma trimenii larval counts during the monitoring period October 2017 to May 2018. Vertical bars represent larvae counts over the seven- to 10-day periods per month

with a cream-coloured oval patch near the tip and a triangular cream-coloured patch near the base. The bright orange hindwings are outlined by a black border. The moth's orange-coloured abdomen matches the hindwings, with a single longitudinal black stripe running down the centre of the abdomen.

Field observations and collection of larvae and pupae in the field were used to further describe the different life stages of $A$. trimenii. The singly laid eggs are circular, with their light-yellow colour against the vine leaves making them almost impossible to see with the naked eye. The eggs become cream-coloured, with irregular brown markings, as they mature. When the first instars eclose, the larvae are off-white to yellow/orange in colour, with an orange head capsule, and $\pm 2 \mathrm{~mm}$ in length. The larvae darken as they feed, later appearing orange in colour. The subsequent larval instars increase in length and develop a distinct colouration of black stripes against the orange body. The head capsule is a red/orange colour, and the length of the body is covered in small hairs/bristles. The hairs along the length of the body are more striking in the relatively large later instar larvae. The rear end of the abdomen has a reddish hump, with two black dots (a possible defence mechanism against predators). The final instar measures $\pm 4.5 \mathrm{~cm}$ in body length, with the entire body darkening, excluding the red head capsule and the red hump at the rear end of the abdomen. It was also noted that larval instars, irrespective of age, become darker (even black) when under stress.

The number of instars is currently unknown. However, the head capsule width of 10 differently sized larvae was measured using a stereomicroscope fitted with a camera and microscope computer software (ZEISS, ZEN, Oberkochen, 
Germany). Such measurements provide some indication of the different larval instars, and can contribute to the understanding of the developmental process from instar to instar. The larval head capsule measurements ranged from 1900 to $4519 \mathrm{~mm}$. Larvae of different sizes, collected from the field, are shown in Fig. 4 to give a general idea of the appearance of the different instars.

When final instar larvae stop feeding, they migrate to the ground via a silken thread and burrow into the soil, where they form soft-bodied prepupae which have a greenish-brown colouration. The prepupae develop into pupae protected by a hardened outer shell/cuticle, which is reddish-brown in colour, typical of most noctuids. The pupae darken as they age, eventually becoming dark brown. The approximate length of the pupae was measured at $1.9 \mathrm{~cm}$, with a width of $1.3 \mathrm{~cm}$. Pretorius et al. (2012) reported approximate pupal length as $2.5 \mathrm{~cm}$. Male and female pupae can be differentiated by characteristic markings on the ventral abdominal terminal segments. Male pupae have triangular markings, while female pupae have rounded markings (Van den Berg, personal communication, 2017).

\section{BEHAVIOUR AND DAMAGE}

Observations in the field show that the early larval instars feed on the new shoots and leaves of the vines and, as they grow and develop, they feed on the older and larger leaves. Larval feeding is quite severe and, when population numbers are high, can result in complete defoliation of vines. The larvae expel a green droplet from the mouth when disturbed and, if disturbed, all the larval stages, excluding the final instar, drop from the leaves and hang suspended by a silken thread. The later instars don a characteristic pose when threatened, with the head flung back so that the thoracic legs are directed forwards. The larvae also display violent curling and uncurling, as well as rapid twisting of their body, when disturbed. The adult moths are nocturnal and most active during the night, although a few of the moths are, sporadically, visible during the day. The moths rest on vine leaves within the canopy during the day, with a few seen resting on the soil mounds surrounding the vines. Diurnal moth mating was observed.

Foliar damage is most visible from November to January. All the larval instars, excluding the final instar level, consume most of the young leaf material, including the succulent tissues, veins and midrib. Larvae measuring \pm $3 \mathrm{~cm}$ in length tend to cause the most severe foliar damage. No alternative host plants were found in the surrounding vegetation during field observations.

\section{TRAPPING AND MONITORING}

Monitoring for insect pests is the first fundamental step to be taken in developing an effective integrated pest management (IPM) programme (Prasad \& Prabhakar, 2012). The forecasting of the presence of insect pests and determining pest population density and distribution in the field are crucial components of IPM, enabling farmers to make costeffective and environmentally sound decisions to minimise crop losses and optimise pest control (Binns \& Nyrop, 1992; Prasad \& Prabhakar, 2012). Pests are monitored by means of various physical trapping tools, such as pheromone, pitfall and light traps, and by visual scouting procedures. Scouting procedures include vine inspection at set time intervals and the classifying of each vine as infested or not. This is done by means of inspecting a predetermined number of leaves and/or bunches of grapes, as was done during the field observations described above (De Villiers et al., 2006; De Villiers \& Pringle, 2008).

Pheromone traps are reliant upon a sex pheromonebased lure to attract specific insect species (Witzgall et al., 2010). Lepidopteran species populations, like those of the false codling moth, Thaumatotibia leucotreta (Meyrick) (Lepidoptera: Tortricidae), and the codling moth, Cydia pomonella L. (Lepidoptera: Tortricidae) - both significant pests of various crops in South Africa, are monitored using pheromone trapsas standard practice. Although the pheromone of the Australian grapevine moth, Phalaenoides glycinae Lewin (Lepidoptera: Noctuidae), has not been produced for use in trapping, the semiochemicals that constitute the sex pheromone have been identified as a combination of 2-phenylethanol and phenethyl acetate (Edgar et al., 1979). Since A. trimenii and P. glycinae both belong to the family Agaristidae, the possibility of the two species sharing the same or similar semiochemicals was considered. A lure, based on the semiochemical ratio identified from P. glycinae and manufactured by Chempak (Pty) Ltd (Paarl, South Africa) was tested in the field during the $2017 / 2018$ season

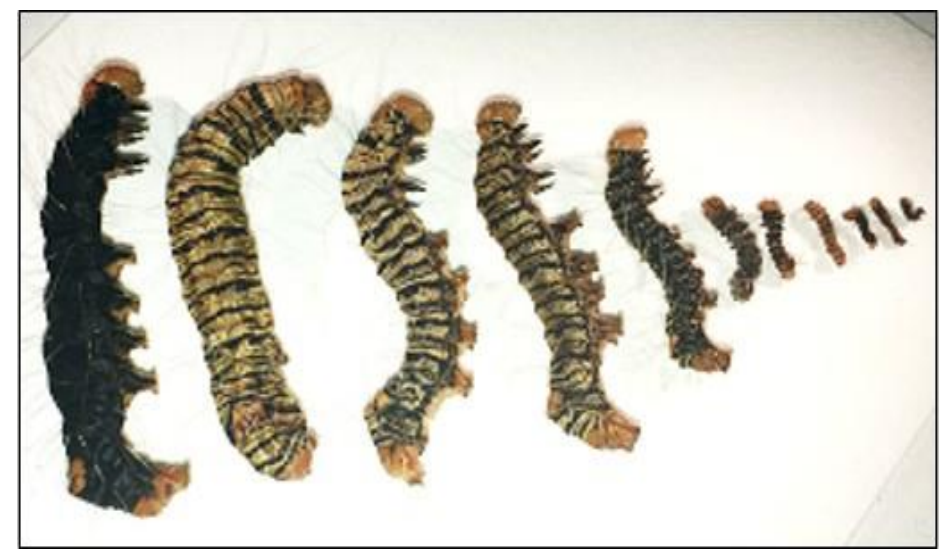

FIGURE 4

Larval stages of Agoma trimenii, from final instar (left) to earliest instar (right) 
in yellow delta traps. Additionally, live bait traps consisting of virgin female moths of $A$. trimenii were tested in the field. Although this method of monitoring is an old practice, it still proves useful in certain monitoring situations. Further illustrations of its usefulness are described in numerous studies of different moth species, including cabbage looper moths, Trichoplusia (Lepidoptera: Noctuidae), and spruce budworms, Choristoneura (Lepidoptera: Tortricidae) (Miller $\&$ McDougall, 1973; Birch, 1977). However, neither of these attractants resulted in the capture of $A$. trimenii in baited traps in preliminary trials (data not shown).

The application of ultraviolet (UV) light traps has proven to be a promising method of surveying nocturnal moth populations. This method exploits the attraction of such moths to artificial light (Jonason et al., 2014). Awareness of contributing factors should increase the likelihood of selecting the right time for the setting of traps to their best advantage, so as to minimise the 'non-productive' effort exerted in the deploying of light traps when no moths are likely to be trapped (Steinbauer, 2003). As A. trimenii displays high nocturnal activity, the potential use of light traps was tested in the field as a possible monitoring option. A light trap emitting blue UV light with a water trap, and a solarpowered inflorescent light in the vine canopy ( $\pm 2 \mathrm{~m}$ high), with white sticky pads in close proximity to the emitted light so that light was reflected onto the sticky pads, were tested in the field on the two table grape farms in the Northern Cape. Traps were checked each morning for a period of three weeks during the growing season, the number of trapped moths were recorded, and the water traps or sticky pads were replaced. Observations indicated that trapping adult moths via a UV blue light trap was three times more effective than the influorescent light during the testing period, attracting and trapping up to 42 moths in one night compared to 12 moths caught by the solar-powered inflorescent light.

\section{CONCLUSION}

What we now know about $A$. trimenii sheds some light on the biology and ecology of this pest and can be implemented to improve control. Since female moths lay eggs in the top parts of the vine canopy, it is important that this part of the vine canopy is monitored closely for early signs of feeding damage. Control carried out in the early stages of infestation will minimise damage and subsequent population increase. In the absence of a pheromone lure for $A$. trimenii, light traps can be used to monitor moth activity, as well as to act as a mass-trapping control measure to reduce population numbers. As the pupae of $A$. trimenii are easy to locate and remain immobile once burrowed into the soil, testing possible control options against them is fairly easy in relation to the other life stages. The pupae cause no damage to the vines, and the overwintering period may be an ideal time for the application of potential biological control agents. However, the protective cuticle of the pupae may inhibit the efficacy of control, and targeted control at the soft-bodied prepupae may be a more viable option. However, ensuring that the control measures act during the short prepupal stage could be challenging. Since control measures against this pest are lacking, it is recommended that an IPM strategy be developed, and the information presented here provides a platform from which an integrated approach for the control of $A$. trimenii can be developed.

\section{LITERATURE CITED}

Australian Museum, 2010. Grapevine moth. Online: http:// australianmuseum.net.au/Grapevine-Moth [accessed 20 June 2017].

Binns, M.R. \& Nyrop, J.P., 1992. Sampling insect populations for the purpose of IPM decision making. Annu. Rev. Entomol. 37, 427-453. doi:10.1146/annurev.en.37.010192.002235.

Birch, M.C., 1977. Response of both sexes of Trichoplusia ni (Lepidoptera: Noctuidae) to virgin females and to synthetic pheromone. Ecol. Entomol. 2, 99-104. doi:10.1111/j.1365-2311.1977.tb00870.x

De Prins, J. \& De Prins, W. 2012. Afromoths, online database of Afrotropical moth species (Lepidoptera): http://www.afromoths.net

De Villiers, M. \& Pringle, K.L., 2008. Developing a generic sampling system for monitoring the key arthropod pests of table grapes, Vitis vinifera $\mathrm{L}$. Int. J. Pest. Manage. 53, 207-217. doi:10.1080/09670870801968872

De Villiers, M., Walton, V., Pringle, K.L. \& Addison, P., 2006. Monitoring system for pests of vines. Department of Conservation Ecology and Entomology, Faculty of AgriSciences, Stellenbosch University, Stellenbosch.

Edgar, J.A., Cockrum, P.A. \& Carrodus, B.B., 1979. Male scent-organ chemicals of the vine moth, Phalaenoides glycinae Lew (Agaristidae). Experientia 35, 861-862.

Jonason, D., Franzen, M. \& Ranius, T., 2014. Surveying moths using light traps: Effects of weather and time of year. PLoS One 9, e92453. doi:10.1371/ jpurnal.pone.0092453

Miller, C.A. \& McDougall, G.A., 1973. Spruce budworm moth trapping using virgin females. Can. J. Zool. 51, 853-858. doi:10.1139/z73-127

Morris, C.A., 2018. Trimen's false tiger moth, Agoma trimenii (Lepidoptera: Agaristidae): Biology and potential control options. Thesis, Stellenbosch University, Private Bag X1, 7602 Matieland (Stellenbosch), South Africa.

Picker, M., 2012. Field guide to insects of South Africa. Penguin Random House South Africa, Cape Town.

Prasad, Y. \& Prabhakar, M., 2012. Pest monitoring and forecasting. In: Abrol, D. \& Shankar, U. (eds). Integrated pest management: Principles and practice. CABI, Wallingford. pp. $41-57$.

Pretorius, J.D., Zaayman, J.L. \& Van den Berg, J., 2012. Confirming the pest status of Trimen's false tiger, Agoma trimenii (Felder) (Lepidoptera: Agaristidae), on grapevines in South Africa. Afr. Entomol. 20, 198-200. doi: $10.4001 / 003.020 .0127$

SATI, 2019. Statistics of table grapes in South Africa. South African Table Grape Industry, Paarl, South Africa.

Steinbauer, M.J., 2003. Using ultra-violet light traps to monitor autumn gum moth, Mnesampela privata (Lepidoptera: Geometridae), in south-eastern Australia. Aust. Forestry 66, 279-286. doi:10.1080/00049158.2003.10674 922

Witzgall, P., Kirsch, P. \& Cork, A., 2010. Sex pheromones and their impact on pest management. J. Chem. Ecol. 36, 80-100. doi:10.1007/s10886-0099737-y 